\title{
TOWARDS CROSS-COUNTRY COMPARABLE REFERENCE BUDGETS IN EUROPE: FIRST RESULTS OF A CONCERTED EFFORT
}

\author{
Tim Goedemé, Bérénice Storms, Sara Stockman, \\ Tess Penne and Karel Van den BosCh*
}

\begin{abstract}
In Europe, reference budgets are increasingly recognised as a helpful tool for policy making and monitoring. If developed in a cross-country comparable way, reference budgets could, in addition, prove to be useful for cross-national learning and contextualising the EU social indicators. However, current reference budgets are not comparable across countries. In this article we report on the first results of a concerted effort to construct comparable reference budgets for adequate social participation in Antwerp, Athens, Barcelona, Budapest, Helsinki and Milan. We start from a single theoretical and methodological framework and carefully track differences in institutional settings, climate, culture, and the availability and prices of goods and services that justify crosscountry variations in the contents and levels of reference budgets. Results indicate that adequate social participation requires access to different goods and services in the six cities, but that, at the same time, the needs to be fulfilled are rather similar, such that
\end{abstract}

\footnotetext{
This article was awarded the Intersentia/FISS prize for the best previously unpublished paper presented at the 2014 FISS Conference held in Sigtuna, Sweden.

All authors are affiliated to the Herman Deleeck Centre for Social Policy at the University of Antwerp, Sint-Jacobstraat 2, 2000 Antwerp, Belgium. The author for correspondence is Tim Goedemé (e-mail: tim.goedeme@uantwerpen.be; phone: +32 326555 55). The authors are grateful to Michael Adler, Jonathan Bradshaw, Bea Cantillon, Diana De Graeve, Eva Lefevere, Peter Saunders, and István Tóth for comments and suggestions on a previous draft of the paper. First results were presented during the 21st FISS International Research Seminar on Issues in Social Security in Sigtuna, June 2014, as well as a number of ImPRovE meetings. The input received by participants helped to considerably improve the paper. Finally, we would like to cordially thank our partners in the ImPRovE project, who developed the reference budgets for Athens (Eleni Kanavitsa, Alexandros Karakitsios and Manos Matsaganis), Barcelona (Elena Carillo Alvarez and Irene Cussó Parcerisas), Budapest (Anikó Bernát, Marianna Kopasz, Bori Simonovits, and Péter Szivós), Helsinki (Lauri Mäkinen and VeliMatti Ritakallio), and Milan (Marco Arlotti and Yuri Kazepov). This study is financially supported by the European Union's Seventh Framework Programme (FP7/2012-2016) under grant agreement n. 290613 (project title: ImPRovE, http://improve-research.eu) and the FWO Methusalem Fund [41/FA040100/FFB2998]. The authors take full responsibility for the contents of the paper and any remaining errors and shortcomings. The views expressed in this paper do not necessarily correspond to those of the funding agencies or the authors of the underlying country reports.
} 
the variation in the level of reference budgets is less than what would be expected on the basis of differences in median household incomes. Results also show that constructing comparable reference budgets requires substantial and intensive coordination. We suggest directions in which our approach to their construction could be improved.

Keywords: adequacy; budget standards; comparability; minimum income; reference budgets; social participation

\section{INTRODUCTION}

Reference budgets are illustrative priced baskets of goods and services that represent a given living standard (cf. Bradshaw 1993; Bradshaw and Mayhew 2011). A number of EU countries have developed reference budgets which measure the cost of a list of core items required for a socially acceptable standard of living within a particular country (e.g. Collins et al. 2012; Davis et al. 2012; Hoff et al. 2010; Kemmetmüller and Leitner 2009; Konsument Verket 2009; Lehtinen et al. 2011; McKay et al. 2012; Preusse 2012; Statens Institutt for forbruksforsking 2011; Storms and Van den Bosch 2009b; Vassileva 2009). In practice, reference budgets are mainly used to define a decent living standard and this implies that they can be used for a variety of purposes, among which the most important are: determining additional income support, settling income maintenance levels, debt rescheduling, financial education, proposing alternative methods for calculating credit scores, and assessing the adequacy of (minimal) wages and benefits. If developed in a cross-country comparable way, reference budgets could in addition help to contextualise EU social indicators of income poverty and financial stress, to monitor the adequacy of minimum income protection schemes in a range of countries and to facilitate crossnational learning in order to design more effective minimum income support measures. Unfortunately, until now existing reference budgets have not been directly comparable across countries due to substantial differences in objectives and methodology (Storms et al. 2014). It is, therefore, difficult to use them in a European context.

In the European project ImPRovE, researchers in six European countries (Belgium, Finland, Greece, Hungary, Italy, and Spain) examined the feasibility of developing cross-country comparable reference budgets on the basis of a common theoretical and methodological framework. In a previous paper, we have outlined our own theoretical and methodological framework for developing cross-country comparable reference budgets (Storms et al. 2013). To the best of our knowledge, this is the first attempt to construct comparable reference budgets in a single concerted effort in Europe. In this paper, we present the first of our results regarding the content, level and comparability of reference budgets developed using this framework, for people living in relatively large cities in the six aforementioned countries (Antwerp, Athens, Barcelona, Budapest, Helsinki and Milan). The selected countries vary greatly in GDP per capita and the size and structure of their welfare state. We discuss in some 
detail the similarities and dissimilarities between budgets across countries and try to explain them. We conclude with a discussion of the lessons learned.

We develop reference budgets which reflect the minimum financial resources needed for adequate social participation. In doing this, we are not attempting to claim that the developed baskets of goods and services necessarily reflect a 'consensus in society'. Rather, we stress the importance of carefully explaining the reasons behind the selection of particular items for inclusion in the baskets or their omission, and the importance of using the best evidence available to find out what constitutes the minimum required for adequate social participation, building on a wide range of data sources. In this way, reference budgets can become a consensus-building instrument regarding the minimum resources required for adequate social participation.

The paper is organised as follows: first we explain the targeted living standard to which the reference budgets should correspond and the target population and model families for which the budgets have been developed. Subsequently, we define more precisely what we mean by cross-country comparability, explain the particular approach we have chosen and discuss its limitations. Next, we describe the method we followed in more detail, before elaborating on the principles that have guided the development of the various 'baskets' of goods and services for a range of 'intermediary needs' that are required in order to participate adequately in society. Finally, we present the content and level of the resulting reference budgets and explain the reasons for the cross-national variations we have identified. We conclude with a discussion of the lessons learned and the directions in which our approach for constructing comparable reference budgets could be improved.

\section{KEY CHOICES}

Self-evidently, for constructing comparable reference budgets, the targeted living standard should be defined in exactly the same way in all Member States. The targeted living standard in the ImPRovE project corresponds to the minimum financial resources required to participate adequately in society. Adequate social participation is defined as the ability of people to adequately fulfil the various social roles they should be able to take on as members of society. With regard to the minimum required financial resources, it is important to note that we focus on out-of-pocket payments made by private households, in addition to what they may already be paying through taxes and social contributions. In other words, we look for the minimum required disposable household income, taking account of subsidised goods and services on which people can rely.

Within this project, the target population is defined as persons of economically active age and children, living in an urban environment (Antwerp, Athens, Barcelona, Budapest, Helsinki and Milan). Given that required goods and services depend heavily on specific living circumstances, fully-specified reference budgets can only 
be constructed for specific hypothetical model family types. The number of model families developed within this pilot project is restricted to four. The family types are:

- A single person

- A single parent with one child

- A couple without children

- A couple with two children

The adults are assumed to be of working age (of about 40 years old). The child of the single parent household is taken to be a boy of about 10 years old, and the children of the fourth household type are a boy of about 10 years old and a girl of about 14 years old. In Finland researchers made use of the results from some previous work and assumed, for this reason, that the second child of the couple with two children was 4 rather than 14 years old.

Furthermore, we make the following assumptions:

- Health: all household members are in good health. The reason for this assumption is not so much that this is the most common health condition (that is debatable), but rather that costs for health care vary enormously depending on the kind and severity of health problems, each having different implications for the needs of the person affected. Therefore, assuming people are in good health offers a good starting point for comparative analysis.

- Competences: family members are well-informed persons, having the necessary competences to be self-reliant and to make the right decisions with regard to their health and safety, able to act economically (they know their social rights and how to access public goods and services, able to compare prices and buy the products with best value for money and able to cook economically and healthily with sufficient variation, etc.).

- Government-provided goods and services: we start from actual provision and actual prices, insofar these are accessible for low-income households.

Finally, we develop long-term reference budgets that should give people access to the targeted living standard for an indeterminate period of time. In other words, the reference budgets include some room for saving in order to gradually replace durables and being able to cover large one-off or annual costs. This implies that we assume that the reference households are an 'on-going concern': that they have access to all goods and services that are included in the reference budgets at the time when they start living on a budget at the level of the reference budgets. In other words, if a young person without any assets moves out to start a new family, the reference budgets would not suffice for covering the initial cost of buying all necessary durables at once. 
From these assumptions, it will be clear that the reference budgets are set at the level of the minimum financial resources required to participate adequately in society. In real-life situations, more resources will usually be needed because people's budgeting capacities are not always optimal, resources are not always spent in the most optimal or economic way, and people are more often confronted with diseases or lack the information that we had access to in constructing reference budgets. These assumptions should ensure that the reference budgets are not subject to the critique that they are 'too high' when using them as a benchmark for assessing the adequacy of incomes ( $c f$. Rowntree 2000 [1901]). Also, the concept of 'adequate social participation', will always remain to some extent elusive when it is translated into a concrete priced list of goods and services. In our view, the assumptions stated above help to narrow down the degree of elusiveness. When working with reference budgets in concrete cases, they need to be adapted (increased) to be sufficient for more realistic real life situations. Finally, the reference budgets developed in this project could offer a useful starting point for constructing reference budgets based on a less restrictive set of assumptions (e.g. regarding the health status of household members, the family's living environment (e.g. rural rather than urban), their competences and access to information, or the household composition).

\section{CROSS-NATIONAL COMPARABILITY ${ }^{1}$}

\subsection{A DEFINITION OF CROSS-COUNTRY COMPARABILITY}

In order to reflect upon the cross-country comparability of social indicators in general, and reference budgets in particular, it is useful to define more precisely what we mean by cross-country comparability. We consider it helpful to make a distinction between procedural comparability and substantive comparability. Procedural comparability means that the same procedures are implemented for measuring a phenomenon or characteristic in different instances - different times or different places. Procedural comparability does not necessarily imply comparability in a substantive sense, which means that the same phenomenon is captured similarly in different social contexts. To assess whether that is the case requires a criterion that is separate from the procedures used, which is often not available, or is too vague to be of much use. If a criterion for assessing substantive comparability is lacking, procedural comparability can be the only guiding principle that can be used to construct an indicator for comparing countries.

For the purposes set forth in this paper, we define substantive cross-country comparability as a situation in which, at the level of the reference budgets, needs for social participation are satisfied at a similar level. This definition implies that the reference budgets should be sensitive to the local context, in order to reflect cross-country variations in the goods and services that are needed as a minimum

For a more extensive discussion, see T. GoEdemé, B. STORMs and K. VAN DEN Bosch (forthcoming). 
for fulfilling the needs related to adequate social participation, and their associated costs for households. At the same time, this definition requires that reference budgets should not differ between countries for any other reasons than those related to relevant differences in the local context. In other words, they may not vary as a result of differences in definition and interpretation of the targeted living standard, the methodology and procedures used to develop the reference budgets or, as a result of the simple fact of research teams working independently. The latter point is important, given (1) the inevitably elusive character of the targeted living standard; and (2) the general lack of robustness of a range of information sources and procedures often used to construct reference budgets (see Storms et al. (2014) for an overview).

In our view, a perhaps more practical definition of substantive cross-national comparability defines it as a situation in which differences between reference budgets are limited to those emanating from cross-country variations in: institutional context; climate and geographical conditions; culture; and the availability, quality and price of goods and services. We briefly elaborate on each of these dimensions, even though we are well aware they overlap to some extent.

i. Institutional differences. These include the availability of publicly-provided goods and services, public guidelines, and any obligations imposed by the government, as well as the way the economy and social life are organised. Examples of the former are typically found in health care, education, child care, social housing and public transport. In addition, institutional differences relate to requirements imposed on, or expected from citizens. Examples of obligations imposed by the government are requirements for finding work, e.g. the maximum time or distance for travel to work, or health care, e.g. required vaccinations.

ii. Climate and geographical conditions. First, depending on the climate, clothing requirements may differ. Since all EU countries experience both cold and warm periods, though to different degrees, this will affect the proportion of warm $v s$. light clothing. Next, the climate will be particularly important for the costs of heating and related items (e.g. insulation). Further, geographical conditions may affect transportation options. In some countries, cycling may be a realistic option, while in other countries or cities, hills, as well as traffic conditions, may preclude this.

iii. Culture. Social expectations regarding the roles that people should be able to play can be expected to differ in important respects cross-nationally. Also, due to cultural habits, persons and households in different countries may meet the same needs with different culturally-determined goods and services.

iv. Availability, quality and price. Cultural preferences, economic development and the purchasing power of populations may all have an impact on the supply of certain goods and services on the market. It goes without saying that prices vary substantially between countries as well. What may be the most economical choice in one country, may be not so economical in another. In all countries, though, the most cost-efficient choice should guide the selection of goods and services. 
One may wonder whether other factors such as cross-country differences in living standards or economic development should be included. We think that they should not be, or if they are, only implicitly. We consider that differences in living standards or economic development between countries should only be taken into account and generate differences in reference budgets for adequate social participation insofar as these differences affect the minimum required for adequately taking the social roles that one should be able to take, through their impact on relevant differences in institutions, culture, and the availability, quality and price of goods and services.

\subsection{APPROACHES TO ACHIEVING CROSS-COUNTRY COMPARABILITY}

The main methodological challenge regarding cross-country comparability consists of identifying a procedure that strikes the right balance between cross-country robustness and sensitivity to the local context. At a minimum, for achieving comparability, exactly the same concepts, methods and procedures should be used across countries. One could argue that the resulting reference budgets fully reflect cross-country differences in the four factors outlined above, only if further specifications of the content of the baskets are avoided, both in terms of goods and services, and in terms of the 'rules of thumb' and criteria for deciding upon the list of goods and services or for pricing the items. This would be one approach to developing comparable reference budgets.

However, many of the procedures and data sources used in the construction of reference budgets (for instance, discussions in focus groups) lack the degree of robustness that would be required to ensure that cross-country differences in the resulting budgets only result from the four factors outlined above. Certainly, at the present moment, limited robustness is an unavoidable characteristic of any model for fully-specified reference budgets, given that so many choices have to be made about the needs to be covered, the number, quality and type of goods and services to include and their life spans, providers and price. For many of these choices assumptions need to be made and often a range of valid assumptions can be imagined. Also, in many cases, information based on systematic observation is lacking, or where normative choices are involved, social norms may not always be fully crystallised, or may be difficult to observe. All these elements would threaten the robustness of reference budgets and the degree of substantive comparability in a situation in which the same methods and procedures were used in all countries, but the venture was otherwise uncoordinated. An additional, though related, problem would be that, in such a set-up, it would often be difficult to identify the reasons for many of the differences between the resulting reference budgets across countries, undermining their usefulness for cross-national learning and policy evaluation.

Therefore, in this project another approach to achieving cross-country comparability has been followed. In addition to carefully specifying and applying all procedures for constructing reference budgets in a similar way, while ensuring that 
the theoretical starting point is the same, we also start from the same list of goods and services in all countries. This list also comprises the arguments why these goods and services should be included (and others excluded), and the rules of thumb (where applicable) that have guided the development of this list. Starting from this list, in a subsequent step, national teams adapt the assumptions (criteria, rules of thumb and others), number, quality, lifespans, providers and cost of goods and services to the local context, insofar as sufficient evidence can be harnessed to justify deviations from the central list with regard to the four factors defined above. The major advantage of this rather standardised approach is that differences across countries reflected in the reference budgets can be traced and carefully explained, and can be used to show, for a number of well-defined household types, the minimum cross-country variation in net incomes needed to reach a similar level of social participation.

This approach also has its disadvantages. There is a risk that some cross-country differences will go unnoticed because researchers do not find sufficient evidence to justify a deviation from the common list, although they might have done so if the reference budgets had been developed independently. As a result, the variation in levels of reference budgets across countries might be biased downwards. Also, the common list that is used as a starting point may have an impact (difficult to trace) on the absolute level of the reference budgets in particular countries. As the starting list was compiled in relatively rich Belgium, reference budgets in poorer countries could be upwardly biased. Conversely, reference budgets of other countries might have been somewhat lower if the starting point had been a reference budget in a poor country. In future work, we intend to apply an approach that is more sensitive to those crosscountry differences that are hard to objectify.

\section{METHODS}

In this project, we developed fully-specified reference budgets, building on a wide range of data sources (see Goedemé et al. (forthcoming) for a comparison of various methods). Figure 1 below summarises the procedure that we followed in order to construct crosscountry comparable reference budgets. The resulting budgets are collected in the Herman Deleeck Centre for Social Policy EU Reference Budgets Database (CSB EU-RBD). Given the large amount and different types of information that are needed to identify which goods and services are required for people to be able to adequately play the social roles they should at a minimum be able to take on, we have applied a mixed-method approach; this approach was elaborately tested in Belgium in various projects over a number of years (2006-2012). The method has been used to construct reference budgets for a wide variety of model families and different regions (and language groups). All projects were carried out in cooperation with a wide range of experts, who were consulted at all stages of the project (e.g. using the Delphi method), and in close collaboration with stakeholder organisations. In addition, the approach involved many rounds of discussions in focus 
groups (now totalling over 40 group discussions in all). Initially the focus groups primarily included people who were experiencing poverty or who had relatively low levels of financial resources (around 60 per cent of the national median income). In the later stages, the membership of focus groups was purposefully mixed with regard to socio-economic background (Storms 2012; Storms et al., forthcoming; Storms and Van den Bosch 2009a; Storms and Van den Bosch 2009b; Van Thielen et al. 2010).

All national teams started from the same targeted living standard and target population, using the same theoretical framework, rules of thumb, quality criteria and list of goods and services. In order to organise the data collection process, we worked top-down from an abstract to a concrete level. First, we clarified our theoretical framework. This starts by using the theory of human need (Doyal and Gough 1991) together with a range of international declarations (e.g. Council of Europe 1996; UN General Assembly 1989), guidelines and regulations to explain the relation between the individual and society, and the central importance of health and autonomy for being able to participate adequately in society. Furthermore, it explains the relation between these central needs and a more concrete set of 'intermediate needs' (e.g. personal care) and their associated functions (e.g. intimate hygiene) that should be fulfilled in order to play the social roles people should be able to take on. We developed reference budgets that cover the following intermediate needs: healthy food, clothing, housing, personal care and health care, safety in childhood, mobility, rest and leisure and maintaining social relations. It should be noted that some important needs are not fully covered by the reference budgets presented in this paper, notably security and life-long learning. It is noteworthy that the list of intermediate needs shares important similarities with alternative lists developed in other ethical-philosophical theories (cf. Alkire 2002). For each of these intermediate needs, a set of more concrete 'functions' was identified and rules of thumb and criteria were developed to translate these functions into detailed lists of goods and services. These were summarised in detailed guidelines regarding how the list should be adapted to the local context. The detailed list of goods and services was organised in harmonised Excel files, together with more details about the function(s) they serve, their provider, price and lifespan. Taken together, the theoretical framework, guidelines and harmonised Excel files constitute what we call the 'common base'.

Second, each national team checked whether this 'common base' was acceptable for their country and, if not, adapted it to the local context. Adaptations to the local situation were informed by, and justified on, the basis of a range of information sources, including national regulations and guidelines, survey data, and other evidence available in the literature. The baskets of food and health care particularly benefited from the input of national experts. In addition, all teams organised at least three focus group discussions in which the feasibility, suitability, acceptability and completeness of the reference budgets were discussed.

Finally, the resulting baskets of goods and services were checked by the coordinating team at the University of Antwerp. Wherever they identified inconsistencies between 
corresponding baskets for different model families, between arguments and the goods and services in the Excel files, or strong differences that were rather weakly justified, they asked national teams to double check the list.

Figure 1. The ImPRovE approach to constructing cross-country comparable reference budgets

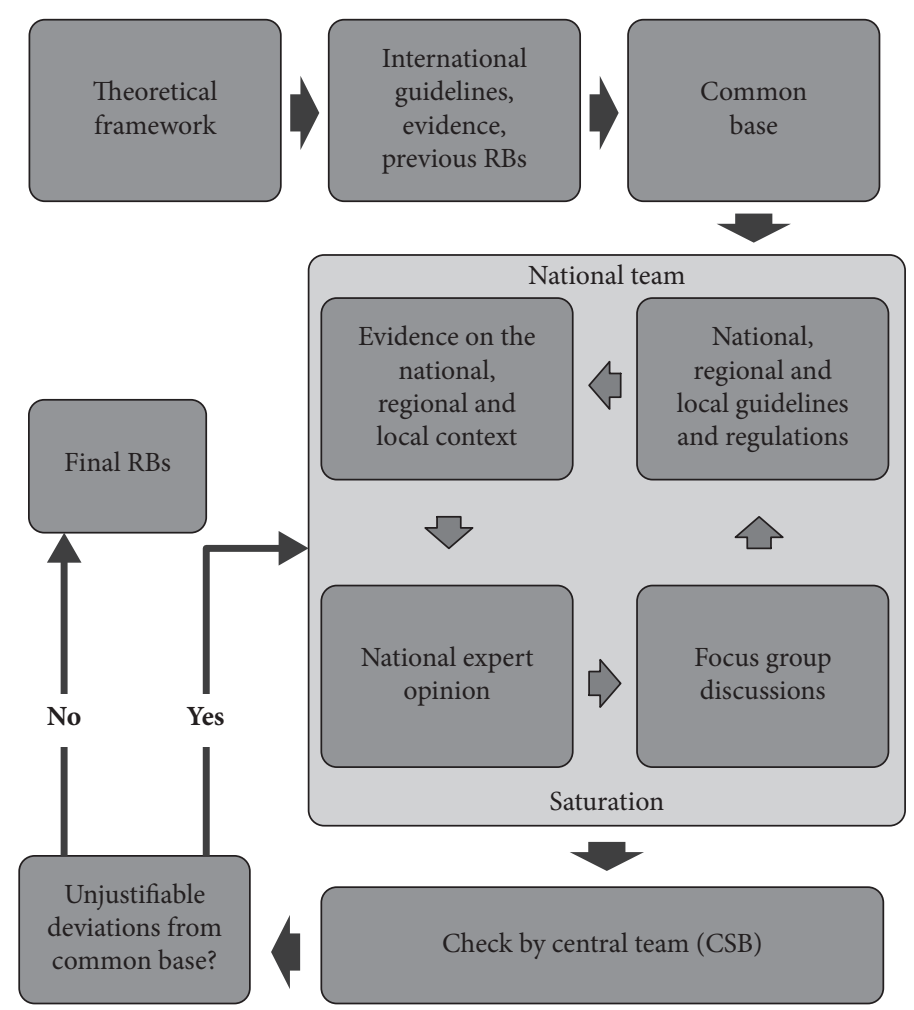

A common procedure was agreed for pricing the goods and services that were included in the national reference budgets. We aimed to set prices that could be justified in a minimum budget while still allowing a certain degree of freedom of choice or autonomy for families. More specifically, as a basis for pricing the items in all countries, retailers were chosen who were well-spread across the country, or, when habitual, a local market was used (e.g. for fruit and vegetables), and for each basket a target price level was agreed (e.g. the third cheapest shirt of a certain quality in a shop). Similarly, for similar products (e.g. clothing and durables) the same lifespan was assumed, if no better information on actual cross-national variations in lifespans was available.

Between April 2012 and November 2014, the international consortium met every six months to discuss progress and problems, and to coordinate the applied procedures. In addition, regular Skype meetings were held. In all countries, at least 
two researchers were responsible for ensuring the timely development of the reference budgets, consultation with experts in particular fields, and the organisation of focus group consultations. More details on the theoretical framework and methodological considerations can be found in Storms et al. (2013).

\section{THE CONSTRUCTION OF THE BASKETS}

In this section, for each of the baskets, we describe in brief, the rationale for including each of the 'intermediate needs' and explaining the rules of thumb, criteria and functions that formed the basis for translating them into a concrete list of goods and services.

\subsection{HEALTHY FOOD}

There is overwhelming evidence of the role of food and nutrition in the maintenance of good health and in the prevention of various diseases (Block et al. 1992; Holick 2006; Joint WHO-FAO Expert Consultation on Diet 2003; Lloyd-Jones et al. 2010; Orchard et al. 2012; Vartanian et al. 2007; Williams 2012). The food basket represents the minimum cost of healthy eating and kitchen equipment. However, food does not only accomplish a nutritional function. The foods that we eat also have an important social and psychological function. Humans gather together around food and celebrate special occasions with special dishes and meals. Food also serves as a way to deal with and express particular kinds of emotions (see, e.g. Arnaiz 2010; Den Hartog et al. 2006; Mennel et al. 1992). Food requirements for fulfilling these functions are covered in other baskets discussed below.

In their 'Scientific Opinion on establishing Food-Based Dietary Guidelines', the European Food Safety Authority (EFSA) (2010) explains why it is not feasible to establish detailed and effective food-based dietary guidelines which could be used at the EU level, referring to wide disparities both in dietary/cultural habits and in the availability of food products between European Member States. Therefore, each national team consulted a local nutritionist in order to draw up a country-specific food basket, based on national dietary guidelines regarding the recommended quantities of various food products. Subsequently, an illustrative menu was developed in correspondence with the recommended quantities and qualities of food. It is important to note that for the construction of these menus, household members are assumed to have the capacities to buy their ingredients economically and cook healthy meals on a daily basis. Finally, the feasibility and acceptability of the food basket was assessed during the focus group discussions and if necessary, adapted to better fit cultural habits (insofar as they were in accordance with food guidelines). Researchers in Finland, in contrast with the other countries, started by developing a daily menu in consultation with focus groups, and this was subsequently adapted by a nutritionist to reflect a healthy diet in correspondence with national food guidelines. The food 
basket also includes the minimum necessary kitchen equipment for preparing, serving, eating, storing and conserving food.

\subsection{CLOTHING}

In order to live healthily and act autonomously, people also need suitable clothing. Clothes serve various functions, of which the most important are arguably to offer protection against the weather, to allow them to appear in public without shame and play various social roles, and to provide individuals with a particular identity (e.g. Crane 2012). In contrast to the food basket, there are few European or national guidelines with criteria for adequate clothing (apart from general consumer legislation about the minimum quality of garments). In all countries, focus groups agreed with the following principles, which were first developed in a Belgian context: clothes, both formal and informal, should as much as possible be multifunctional and allow people to play their various social roles; the determination of the minimum number of clothes should be based on standards of hygiene, national cultural habits and realistic practical considerations (e.g. the time required to wash and dry cloths). As clothes are a reflection of individuals' identity, it is important that people should be able to have sufficient choice and should not be dependent upon the range on offer in one particular shop, upon what is available at end-of-season sales, or be compelled to wear second-hand clothes (insofar as these behaviours were not accepted in focus groups). Since, in all countries, end-of-season sales are organised at least twice a year, we calculated a 10 per cent sales reduction on all new clothes. Besides clothing, the basket contains a number of essential auxiliary tools for the maintenance and storage of clothing and shoes.

\subsection{HOUSING}

Housing is generally recognised as a basic need. Housing should provide adequate protection and security against disease bearers, and adverse weather conditions. Furthermore, a dwelling should contribute to a hygienic lifestyle, for which clean and hot water are required, as well as adequate sewerage. To prevent, inter alia, illness and depression (Doyal and Gough 1991; Murie 1983) households should have enough space to live decently and should be supplied with lighting and heating. Finally, adequate housing is intertwined with various other functions such as being able to invite friends and family once in a while (insofar as this is part of the national culture) or to provide children with a secure home where they can play. Several types of costs may be associated with having access to a quality dwelling, such as those for cleaning products, and tools and materials to maintain the dwelling. In addition, the household may require structural insurance related to the dwelling and may face additional costs for mandatory services, such as sewage removal.

In principle, the calculation of the cost of adequate housing is no different from that of the other baskets. However, housing is different from, for example, clothing 
in that it is highly heterogeneous - every dwelling is different from any other in some respect - local price variations may be quite substantial and the market for housing has low transparency. Therefore, we make use of representative survey data (EU-SILC 2012) to estimate the cost of a modest but adequate dwelling which meets some minimum quality criteria that are generally recognised as essential standards of adequate housing. More precisely, using a subsample of households for the densely populated areas in the region in which the reference cities are located, we identified the cost of adequate housing at the $30^{\text {th }}$ percentile (in other words, about 70 per cent of the dwellings that meet the quality criteria are more expensive or involve higher costs). For private sector tenants, separate estimates were made of rent and other housing costs; for outright owners we estimated all housing costs. These estimates were based on quantile log-linear regression models for each country, in which the size and other characteristics of the dwelling and household situation were included (for detailed results, see Van den Bosch et al., forthcoming). The resulting estimates were uprated to 2014 price levels, making use of the harmonised consumer price indices for housing costs, published by Eurostat.

\subsection{PERSONAL CARE}

Personal care is important as it contributes to combatting disease as well as serving a psychological and social purpose, i.e. it instils a sense of self-value and self-respect (Curtis and Cairncross 2003; European Centre for Disease Prevention and Control 2011; Petersen 2003). Without adequate personal hygiene, there is a danger of social exclusion due to a perceived failure to adhere to the social norm. Due to the lack of European and national guidelines, the starting point for the personal care basket was a list of items essential for a proper daily hygiene, compiled by a Belgian health expert (Diepstraten 2009). The list includes the necessary items for body care (e.g. soap and towels), oral health (e.g. a toothbrush and tooth paste), hair care (e.g. shampoo, comb, brush, visits to a hairdresser, shaving equipment etc.), intimate hygiene (e.g. tampons and sanitary napkins) and hygiene (e.g. toilet paper, a toilet brush and a toilet rubbish bin). In each country the list was checked by a health expert, and in all countries the experts suggested only minor adaptations. After discussions in focus groups, a lump sum for perfumes and cosmetics was also calculated, as their use can be considered widespread across cultures and as make-up is sometimes expected for particular events and professional situations.

\subsection{HEALTH CARE}

As discussed above, we assume members of the model families to be healthy people without severe medical problems, to live in healthy socio-economic circumstances, and to have the resources to access health care and to be well informed about its effective use. Accordingly, only a minimum of basic medical facilities is included, so that people 
are able to consult a doctor when needed or to apply basic first aid to themselves and other family members. As this will not be enough for all persons and especially not for those living on a low household income (Commission on Social Determinants of Health 2008; JP Mackenbach 2006; J. Mackenbach et al. 2005; Willems 2005), this budget will be an underestimate of the real costs for many families. Nevertheless, we decided to estimate as precisely as possible the cost of remaining in a good health for people who are already healthy. As a result, these budgets should be used carefully and critically assessed when used in a policy context, taking into account the real financial costs for ill and disabled people.

For constructing the health care budget we took into account disease prevention, trauma due to accidents, contraception and everyday diseases, focusing solely on acute diseases that are less severe. The list of goods and services needed for day-today care was quite limited, in part because it assumed that the people in question made responsible choices regarding health care. The original basket in Belgium was constructed in close collaboration with a wide range of health experts, and, after several rounds of discussions and adaptations, approved by the Flemish Association of General Practitioners (Domus Medica). In this project, we did not set up similar rounds of discussions with health experts in every country, but focused instead on adapting the list of items and their 'out-of-pocket price' to the particular health care systems of each country. In general, the reference budgets cover several visits to a general practitioner a year, a consultation with a dentist, some medicines for common diseases (e.g. fever medication and antibiotics for a child), a home medicine chest for treating some mild infectious diseases and other common acute health problems, as well as some preventive items, such as obligatory or publicly recommended vaccinations, screenings and contraceptives. Finally, the healthcare budget also covers compulsory health insurance costs and an additional (not compulsory but advisable) hospitalisation insurance (only relevant in Belgium).

\subsection{REST AND LEISURE}

Rest is essential for good health: it allows the body and mind to recuperate and recover. A good night's sleep is ensured by following a proper lifestyle and using suitable sleeping equipment (Coleman and Isoahola 1993; Hancock 2012; Hyyppa et al. 2006; Konlaan et al. 2002). Due to the paucity of guidelines at a European as well as at national levels regarding quality requirements for beds and amenities, common criteria were agreed upon regarding the kind, the characteristics and the number of items included. In all countries, the same items were commonly purchased in an accessible shop like IKEA. As a result, country differences in the rest basket arise purely from small variations in the prices of these items.

In addition to a proper sleep, leisure contributes to physical, social, and emotional health (Coleman and Isoahola 1993). Moreover, taking an active part in organised groups and associations seems to be protective against all kinds of non-communicable 
diseases (Hancock 2012) and even against all-cause mortality (Hyyppa et al. 2006; Konlaan et al. 2002). For the specification of this basket, we drew on a literature study as well as legislative and policy initiatives, but the most substantial input was from the focus group discussions. On the basis of this information, all countries recognised the need for a holiday budget (see also Gibson and Yiannakis 2002; Toerisme Vlaanderen 2007); a budget for domestic leisure (see also Corijn and Lemmens 2007); and a budget for participating in social and organised leisure activities (the importance of participation in social and cultural activities, both for the individual and for society has been shown in a wide range of studies, including Arrow 1972; Bourdieu 1980; Corijn 2000; Fukuyama 1995; Giordano and Lindstrom 2010; Kawachi et al. 1999; Laaksonen 2010; Portes 1998; Putnam 1993; Stolle and Hooghe 2005). ${ }^{2}$

\subsection{SAFETY IN CHILDHOOD}

Growing up well and experiencing a safe and secure childhood is a basic need, internationally recognised and written down in the international Convention on the Rights of the Child (CRC) (UN General Assembly 1989). In order to be able to act autonomously when they reach adulthood, children need love, praise, recognition and positive feedback. Moreover, they need a variety of new experiences and a gradual broadening of responsibilities in order to be able to develop cognitively, emotionally and socially (Doyal and Gough 1991; WHO 1982). The starting point for developing a concrete list of items was an extensive consultation of Belgian youth experts from academia and NGOs that promote the well-being of children, using the Delphi method. Subsequently, national teams adapted the list on the basis of survey information regarding habits and common practices, and focus group discussions. The following items were generally included: a family trip, a budget for celebrating birthdays and participating in cultural or other activities, toys, some pocket money, a computer with an internet connection, access to the local library and, most importantly, education. It is important to note that, currently, no childcare costs are included in the total budget for a safe childhood.

\subsection{MAINTAINING SIGNIFICANT SOCIAL RELATIONS}

Humans are social creatures and social relationships enable them to develop their own identity (Butter 1999; Thoits 1983). Moreover, a supportive social network of friends and family can help people to solve all kinds of everyday practical and emotional problems. It is hard to express in material terms what is minimally required in every country for

2 A budget to take part in cultural life can also be justified on the basis of international, European and national legislation. See, for instance, Article 27 of the 1948 Universal Declaration of Human Rights, Article 5, UNESCO Universal Declaration on Cultural Diversity, Article 15 paragraph 1 (a), United Nations Committee on Economic, Social and Cultural Rights of the Economic and Social Council of 2009, Article 2-3 and 5 of the 1954 European Cultural Convention, the 1984 European Declaration on Cultural Objectives of the Council of Europe, Article, 9-11, 13-14, 21-23 of the 2000 Charter of Fundamental Rights of the European Union and the 2007 Fribourg Declaration on Cultural Rights. 
the maintenance of relationships, especially because of the lack of formal norms and guidelines. All countries started from similar criteria, which were largely based on Belgian focus groups decisions, and discussed in this project with the participants of the focus groups in all countries. A budget for the following activities was included: for inviting family and friends to visit once in a while, for cheering up the home (e.g. candles and lampshades), for going out for a meal or buying take-away food every now and then, for communication technologies, for celebrations; and for citizenship obligations (e.g. to cover the cost of an identity card). To define the exact list of items, national teams relied principally on the focus group discussions, enriched by survey data on national habits.

\subsection{MOBILITY}

In order to be able to fulfil different social roles, people need to be mobile. Accessible transportation is an essential condition for the fulfilment of many other intermediate needs presented by the other baskets. To construct country-specific and comparable mobility budgets we followed a standard procedure: all countries calculated the cost of public transport and the cost of a bicycle. As stressed earlier, we assumed all household members to be healthy and to live in big cities with extensive public transport systems. Hence, to be sufficiently mobile, a car was assumed to be unnecessary. We calculated a separate mobility budget including all costs of insuring, driving and maintaining a small second-hand car, taking account also of its depreciation in value, to allow for cases in which people are not able to fulfil their social roles adequately without a car.

\section{THE TOTAL BUDGET}

We first discuss the total budget and the relative weights of the various baskets of goods and services within it. Subsequently, we elaborate on the reasons for crosscountry differences in the budgets.

\subsection{AN OVERVIEW}

The resulting reference budgets were priced during the first half of 2014 and are shown in Figure 2. For Budapest, we fixed the exchange rate at $300 \mathrm{HUF}$ to the euro. It is important to note that in the figure below, housing, child care costs and the costs of a car are excluded, and that security and life-long learning are not (fully) covered by the budgets presented here. From Figure 2 it can be observed, as one would expect given price level differences and differences in median household incomes, that, for all model family types, the reference budgets are highest in Helsinki and lowest in Budapest. Yet, the variation of these reference budgets across countries is much smaller than that of median incomes. In comparison with national median equivalent disposable incomes (the income concept used for measuring at-risk-of-poverty in the EU), the level of reference budgets for a 
single person household varies from about 28-33 per cent of national median incomes in Antwerp, Helsinki and Milan, and about 41 per cent in Barcelona, to 54 per cent in Athens and 72 per cent in Budapest. ${ }^{3}$ If the cost of renting a modest but adequate private sector apartment is then added, these percentages become roughly 55 per cent for Antwerp and Helsinki, 70 per cent for Milan, 90 per cent for Barcelona, 95 per cent for Athens and about 125 per cent of the median equivalent disposable household income for Budapest. ${ }^{4}$ Except for Athens, these percentages are substantially lower if one includes housing costs for outright owners rather than those for tenants, ranging between about 38 per cent for Antwerp and Helsinki and about 100 per cent of median incomes for Athens and Budapest (see also Figure 3). The estimated housing costs, however, must be interpreted with caution, given the large differences between housing markets and housing cost structures across Europe, and important variations within each country and city.

Figure 2. Reference budgets for adequate social participation, without housing costs, for Antwerp, Athens, Barcelona, Budapest, Helsinki, and Milan, euros per month, 2014

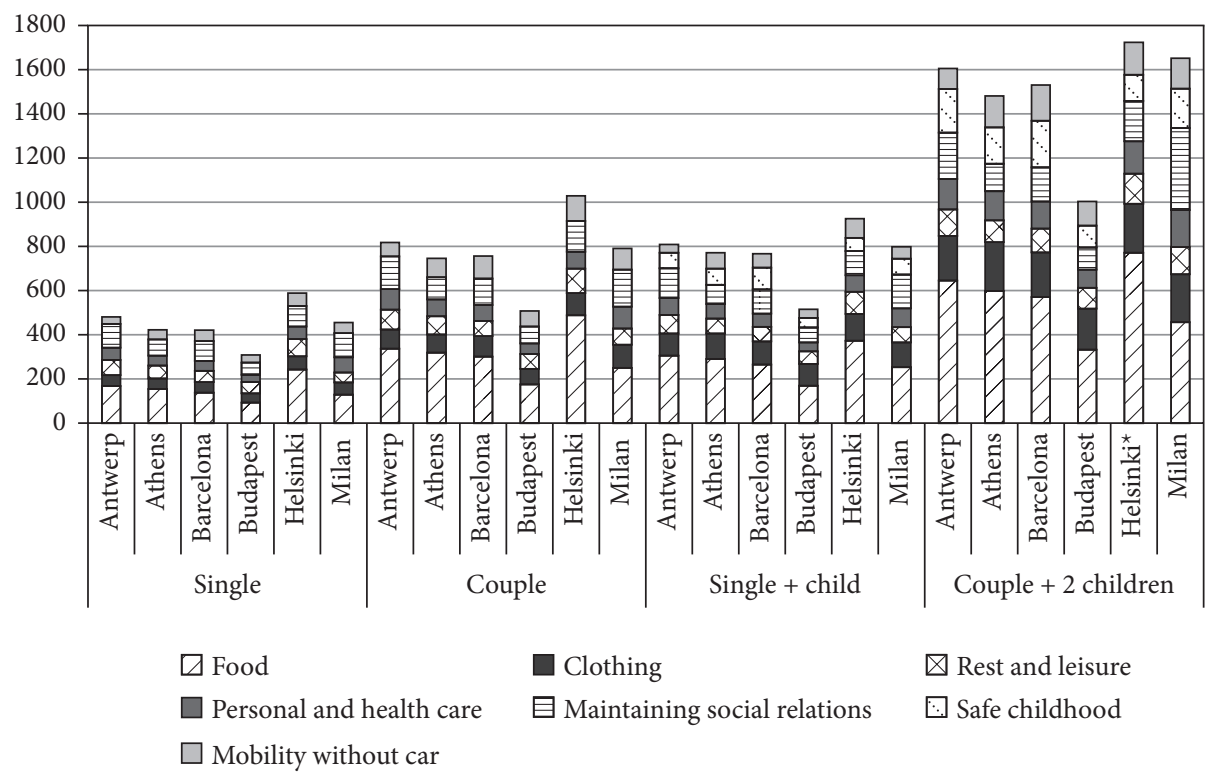

Notes: Adults in single and single parent households are assumed to be female. For Budapest, the exchange rate used is 300 HUF to the euro.

*The second child in Helsinki is assumed to be 4 years old, whereas for the other cities the second child is assumed to be about 14 years old.

Source: CSB EU Reference Budgets Database, own computations.

\footnotetext{
3 The RBs are deflated to price levels of 2011 on the basis of changes in the average consumer price index and compared to the national median income of 2011, measured with EU-SILC 2012 (as published by Eurostat).

$4 \quad$ With housing costs revalued at 2011 prices using the housing-specific price index and the overall consumer price index for the other baskets.
} 
Figure 3. Total housing costs at the 30 th percentile for a modest but adequate dwelling in Antwerp, Athens, Barcelona, Budapest, Helsinki, and Milan, euros per month, 2014

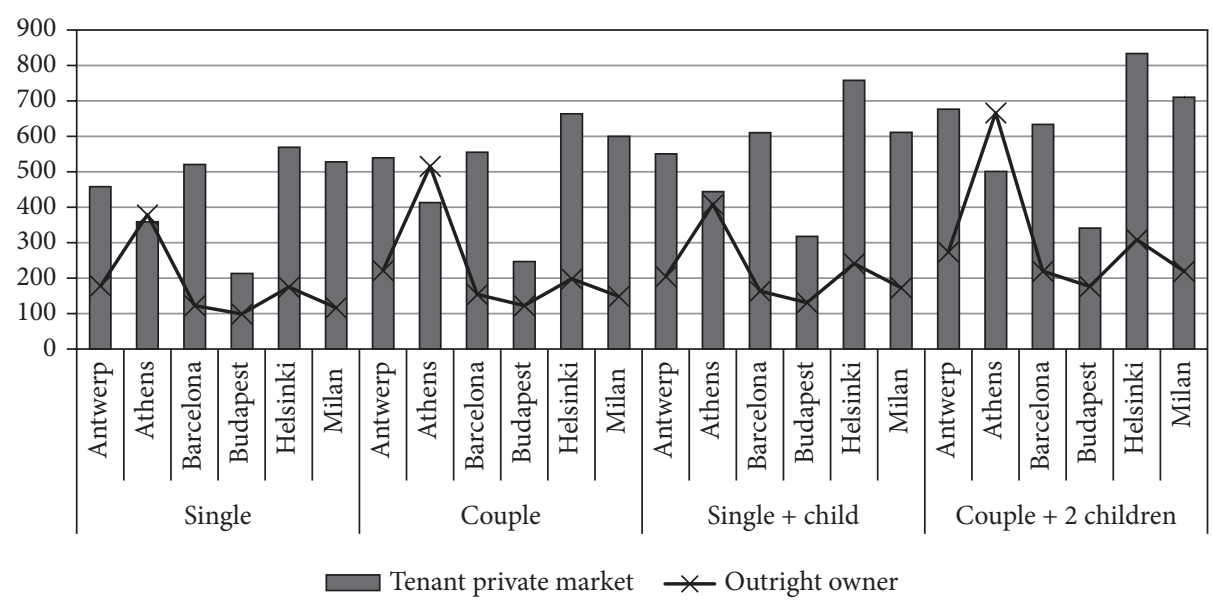

Notes: Housing costs are updated to price levels for the first half of 2014, making use of the harmonised consumer price index for housing, water, electricity, gas and other fuels. For Budapest, the exchange rate used is 300 HUF to the euro.

Source: EU-SILC 2012 UDB revl, Consumer price index from Eurostat online database, own computations.

Unsurprisingly, the weight of the various baskets relative to the total budget depends strongly on the assumed tenure status and assumptions regarding the need for a car, as well as the composition of the household. Generally speaking, as one would expect, the larger the household size, the lower the weight of the housing costs. If a car is left out, the housing budget accounts for between 12 per cent and 45 per cent of the total budget in the case of outright owners, and between 24 and 55 per cent of the total budget in the case of private sector tenants. Apart from housing, the food basket (which includes kitchen equipment) accounts for the largest share. With housing costs left out, its share ranges between 28 per cent for a couple with two children in Milan and about 47 per cent for a couple without children in Helsinki. In the case of single householders and couples, maintaining social relations accounts for the second largest share (housing excluded), whereas for households with children, maintaining social relations or clothing account for the second largest share, depending on the city. An exception is Barcelona, for which, in the case of a couple with two children, the basket relating to safety in childhood accounts for the second largest share. Roughly speaking, the other baskets account for a similar share of the total budget, even though some variation is apparent in their overall weights across cities. Obviously, the weight of mobility in the total budget is generally much higher in cases for which a second-hand car is included (e.g. in most cities, for single people, this cost could easily exceed the cost of the food basket, a finding which underlines the importance of the availability and accessibility of public transport). 
When comparing the reference budgets of different household types, one can identify the potential economies of scale generated by people living together. This can provide important information for assessing the appropriateness of the equivalence scales used for poverty measurement (such as the modified OECD equivalence scale) or for setting benefit levels. Initial results show that the cost generated by the presence of a child in the household, in comparison with that of a single person household, is clearly higher than what is implicitly assumed in the modified OECD equivalence scale, especially in the case of outright owners. Further analysis is clearly warranted to better document and comprehend cross-country variations in economies of scale and the appropriateness of the most commonly used equivalence scales for the measurement of poverty and inequality.

\subsection{UNDERSTANDING THE DIFFERENCES ACROSS COUNTRIES AND CITIES}

As mentioned earlier, we define the targeted living standard as the minimum financial resources for being able to fulfil the social roles one is expected to take as a member of a particular society. As this exercise makes clear, the boundaries of societies are not clearly delineated, and societies can be multi-layered, with international, European, national, regional and local institutions and cultural expectations all impacting upon the lives of individuals (c.f. Mau and Verwiebe 2010). This is also reflected in the reasons behind the variations in the reference budgets across the six cities, with some of these reasons generated at the national, some at regional and some at the very local level.

Climate has an obvious impact on the composition of the clothing basket. For instance, wellington boots and a decent raincoat were included for rainy Antwerp and snowy Helsinki, but not for the other cities. Further, Belgians can wear most of their clothes throughout the year, whereas more variation in clothing is needed in countries with more pronounced seasons, as is the case for Athens, Barcelona, Budapest and Milan. The only other difference across cities on the basis of climate differences, was the inclusion of hand cream for winter periods in the personal care baskets for Budapest and Helsinki. Climate could be expected to play an important role for housing-related costs (especially heating), but the relationship seems to be mediated by other factors, such as the structure of the utilities market, and the characteristics and quality of the housing stock. Other geographical factors do not appear to have had an impact on the contents of the baskets of goods and services, which is not surprising given the choice of cities for the model families.

In contrast, institutional differences regarding the availability and accessibility of publicly-provided goods and services have important effects on the cost of health care (visits to a general practitioner and medicines), the cost of education (high in Barcelona, low in Helsinki), and public transport (high in Helsinki, Barcelona and 
Milan, low in Antwerp). ${ }^{5}$ Regarding health care, for instance, in Antwerp people have to pay an out-of-pocket amount for a visit to a general practitioner, whereas no such costs are charged in Athens, Barcelona, Budapest, Helsinki or Milan. In addition, the number of home visits by a general practitioner was reduced for Budapest, as this is a rather uncommon practice. At the same time, though, an informal payment to the visiting general practitioner was included. This was explained on the grounds that this is a widespread practice in Hungary, as it gives patients the feeling that they will get proper treatment, including being paid sufficient attention as well as being treated politely, and because deviation from the custom may make patients feel apprehensive (c.f. Gaál et al. 2011). Institutional variations in terms of public guidelines and regulations appear to be particularly relevant in relation to the food basket, and to explain much of the variation in the contents of the basket. It is particularly striking that in Greece, Spain and Italy significantly larger quantities of meat, fish and fruit are recommended than in the other countries. At the same time, recommendations regarding the prevention of health problems seem to be rather uniform across the six cities under consideration.

In conjunction with differences in food guidelines, cultural habits regarding food have an important influence on the composition of the food basket, but not as much on its total cost. The same is true for cultural habits and social expectations regarding leisure activities, and maintaining social relationships. For instance, norms for the type of low cost accommodation for a five-day domestic holiday vary across cities, reflecting cultural habits (a caravan on a campsite for Antwerp and Helsinki versus a low cost hotel in Athens, Barcelona, Budapest, Athens and Milan). Also, in Antwerp and especially Helsinki it is common to hire a babysitter when parents go out, whereas in Athens, Budapest and Milan parents rely usually on relatives (who do not charge for babysitting). It is noteworthy that the Finnish focus groups expressed a preference for including high quality clothing in the reference budgets. Therefore, the reference budgets for Helsinki contain more expensive clothing of higher quality. However, given that the lifespan of these clothes is longer, the effect on the total cost of the clothing basket is strongly attenuated. In contrast, the reference budgets for Budapest include more garments bought in second-hand shops, a decision endorsed by focus groups on the grounds that buying and wearing second-hand clothing is a widespread practice, even among higher income groups. Helsinki differs also from the other cities in including a regular visit to a sauna, as this is considered to be an integral part of Finnish culture. Finally, in the basket for safety in childhood in Budapest, relatively little pocket money for children was included, as it was pointed out that this practice is much less common in Budapest than in the other five cities.

Even though we cannot precisely quantify the impact of price differences, as the choice of products is not exactly the same across countries, it is clear that price

That is, especially for adults. In Antwerp, Budapest, Helsinki, and Milan, children under the age of 12 can make use of free public transportation. 
differences are an important source of variation across countries. Some remarkable price differences include the relatively high cost of clothing in Helsinki and Milan, and the relatively low cost of membership of youth associations and sporting clubs in Budapest. Particularly striking is the variation in housing costs, which is due to differences between the particular structures of the housing market in each of the regions under consideration.

The differences in price levels deviate to an important extent from those one would expect on the basis of the price level indices published by Eurostat (c.f. Eurostat online database). This is probably because the official consumer price indices refer to average household consumption patterns and to average prices, rather than to consumption patterns corresponding to those used in generating the reference budgets and 'low prices'. One major obstacle for cross-country comparability though, remains the choice of shops and providers and the difficulties of, in effect, carrying out a price survey. Small differences in the choice of shops or the choice of items can sometimes result in high differences in prices. For products that are usually bought from large retailers whose shops are located across the city and with rather clear quality/price profiles, the choice of retailer is relatively easy to determine, but, where the market is less transparent, it is more difficult to make an appropriate choice. Therefore, it would be useful in the future to explore the possibility of making use of a representative price survey, such as the one used for constructing the consumer price index, to identify low but adequate prices in all cities, and by extension entire countries.

\section{DISCUSSION AND CONCLUSION}

In this article we report results of the first attempt - to our knowledge - to develop cross-country comparable reference budgets. This on-going exercise, part of the FP7-funded project ImPRovE, involves six European countries. We present results for hypothetical families living in Antwerp, Athens, Barcelona, Budapest, Helsinki, and Milan. The references budgets were designed to correspond to the minimum income that is needed for adequate social participation. Adequate social participation was defined as the ability of people to adequately play the various social roles they need be able to take on as members of society. The reference budgets are constructed for four hypothetical households: a single woman, a couple, a single parent with one child (aged about 10 years) and a couple with two children (aged about 10 and 14 years old). Other characteristics of the model families are that the adults are of economically active age, families live in a big city, all household members are in a good health, and family members are well informed and are competent to manage the family budget efficiently. The work was carried out by national teams in each country, while the Belgian team (which includes the authors of this paper) coordinated the project. It should be stressed that we do not claim that the results for these cities are representative of the countries in which they are located. Even though the list of goods 
and services in many cases was determined by regional or national factors (e.g. the cost of health care and education), the need for and the prices of goods and services can differ strongly within countries, especially between rural and urban areas.

Obviously, in order to maintain comparability across cities, the same method was used everywhere. This implies that we relied on a single theoretical framework and used common procedures, rules of thumb and underlying criteria about the number, quality, life spans, providers and cost of goods and services that people need as a minimum for adequate participation in society. However, we recognise that many of the methods and procedures used in the construction of reference budgets do not always unambiguously lead to a single result. Often, several choices are possible which appear equally reasonable. Results can also be influenced by random factors, e.g. by the chance composition of focus groups. Because of this lack of robustness, allowing national teams to proceed on their own, without further standardisation, would probably have resulted in a myriad of differences between reference budgets, even if the teams had applied the common method with the utmost scrupulousness. The reasons for these differences would have been obscure, which implies that it would not have been clear whether and how they could be justified, reducing their informative value for cross-national learning and policy evaluation. In order to avoid such unexplained and unwanted variance, all country teams started out with a common list of goods and services, which they adapted to the local context, using various kinds of evidence, including knowledge about institutions, national guidelines, survey results and focus group discussions. The list was organised according to intermediate needs, adapted from the definition provided by Doyal and Gough (1991), and indicated the functions the items were supposed to serve. Any deviation from the common list had to be justified by reference to one of four kinds of differences between countries: between institutions, geography and climate, culture, and availability, quality and price of goods and services.

The total amounts of the reference budgets (without housing costs) varied across cities, often, though not always, in line with, although much less than, national median equivalent disposable household incomes. In comparison with national median equivalent disposable incomes, the level of reference budgets for a single person household is lower in Antwerp, Helsinki and Milan than in Barcelona and much lower than in Athens and especially Budapest.

Perhaps the most important result of this - as yet unfinished - study is that the procedures proved to be workable. As illustrated above, national teams were able to decide which items on the common list should be retained, which ones should be dropped, and which ones needed replacing, and, in the latter case, were able to find appropriate substitutes. In this they were helped by the fact that the common list mentioned the functions that goods and services should serve. Focus groups could have meaningful discussions about the common basket, and offered sensible reasons for adapting it to local circumstances. Thanks to our decision to start within each country from a 
common basket, we were in a much better position to explain and justify differences in the baskets of goods and services across cities than we would otherwise have been.

It is too early to draw many substantive conclusions from the reference budgets presented in this article. At this point we want to draw attention to the following findings. First of all, the minimum income needed for social participation clearly depends on the supply of free or subsidised goods and services by the government. Even households composed of persons who have no particular health problems have to pay substantially more for routine health care in some countries than in others. While this can also be revealed by other kinds of studies, ours has the advantage that the impact of out-of-pocket health expenses is seen within the context of the total household budget, while at the same time keeping use of health care constant across countries. In a similar way, we identified the important impact of differences in costs to households associated with education and public transport. Second, although more in-depth analysis is required, our initial results indicate that the commonlyused modified OECD equivalence scale tends to be too rough to estimate the extra costs for supplementary household members in various living situations. The cost of children in particular seem to be underestimated, at least in relation to the minimum level of income needed for adequate social participation.

Self-evidently, our study has a number of limitations and problems, and we here mention some of the more important ones. First, as we explained in section 3, it is possible that the common basket imposed too tight a restriction on the resulting reference budgets, and that not all relevant differences in national contexts were taken into account. In this sense, one might argue that our results represent a lower bound on the actual variation across countries in the amount of income that is needed for social participation. Second, the common basket originated from one particular country - Belgium - and it is possible that if it had instead been drawn up in, say, Budapest, this would have led to different reference budgets. Yet, the impact of the chosen starting point should have been limited by the organisation of the common basket into intermediate needs and the references to the functions the goods and services should serve. These intermediate needs and functions are less country-specific than the goods and services themselves. Nonetheless, it would be useful to reflect upon an approach that would be more sensitive to the local context, without compromising too much on robustness. In addition, in the future it may be useful to consider starting from a common list of goods and services which does not originate from one single country, but from some 'greatest common denominator' of a range of countries.

Third, pricing the items in a comparable way in all cities turned out to be more problematic than we had expected. For example, clothing should ideally be priced in country-wide chains at or near the low end of the market, which offer some choice as regards quality and price, but such chains do not exist everywhere. For some items we observed large price variations which are sometimes difficult to make sense of. Using price information collected by national statistical institutes, or cooperating with such institutes in determining price levels, might improve the validity and the transparency 
of pricing data, which are of course crucial. Also, more research is needed regarding the lifespan of durables.

Fourth, not all baskets of goods and services were fully discussed in focus groups due to the fact that we only had the time and means to organise three such groups in most cities. Also, differences between model families were not discussed in the focus groups as all participants were parents with children. Especially for the baskets 'maintaining social relations', 'safety in childhood' and 'rest and leisure' which relied less than the others on existing regulations, guidelines or scientific knowledge, and where cultural differences may be important, country-variations or the lack of these, could not always be fully explained. Conducting more focus groups, in order to discuss all matters until saturation is reached, while allowing for more interaction between the research process and the focus group discussions, could improve the validity and reliability of the results. Even so, the fact remains that the views expressed in focus groups are not necessarily representative of the considered opinions of the population as a whole and should not be used as a shortcut about issues on which better data are available.

\section{REFERENCES}

Alkire, S. (2002) 'Dimensions of Human Development', World Development, 30(2), 181-205.

Arnaiz, M.G. (2010) 'Alimentación y cultura en España: una aproximación desde la antropología social', Physis Revista de Saúde Coletiva, 20(2), 357-386.

Arrow, K.J. (1972) 'Gifts and Exchanges', Philosophy and Public Affairs, 343-362.

Block, G., Patterson, B. and Subar, A. (1992) 'Fruit, vegetables, and cancer prevention - a review of the epidemiologic evidence', Nutrition and Cancer: an International Journal, 18(1), 1-29.

Bourdieu, P. (1980) 'Le capital social', Actes de la recherche en sciences sociales, 31, $2-3$.

Bradshaw, J. (1993) Budget standar and $d s$ for the United Kingdom, Alderschot: Avebury.

Bradshaw, J. and Mayhew, E. (2011) The Measurement of Extreme Poverty in Europe, Europeaan Commission, DG Employment, Social Affairs and Inclusion.

Butter, M. (1999) 'Sustainable Development and Women's Health. Implementation of the Cairo ICPD Programme of Action in the Netherlands', University of Groningen.

Coleman, D. and Isoahola, S.E. (1993) 'Leisure and Health - the role of social support and self-determination', Journal of Leisure Research, 25(2), 111-128.

Collins, M.L., Mac Mahon, B., Weld, G., et al. (2012) A minimum income standard for Ireland. A consensual budget standards study examining household types across the lifecycle, Dublin: Policy Institute. 
Commission on Social Determinants of Health (2008) Closing the gap in a generation: health equity through action on the social determinants of health. Final Report of the Commission on Social Determinants of Health, Geneva: World Health Organization.

Conijn, E. (2000) Vrije tijd werkt ook over de verhouding arbeid en vrije tijd in de twintigste eeuw, Brussels: Koning Boudewijnstichting.

Corijn, E. and Lemmens, S. (2007) Het sociale van cultuur. Lokaal cultuurbeleid en gemeenschapsvorming, Brussels: Cultuur Lokaal.

Council of Europe (1996) European Social Charter (Revised), Strasbourg.

Crane, D. (2012) Fashion and its Social Agendas: Class, gender, and identity in clothing, Chicago, IL:University of Chicago Press.

Curtis, V. and Cairncross, S. (2003) 'Effect of washing hands with soap on diarrhea risk in the community: a systematic review', Lancet Infectious Diseases 3(5), 275-281.

Davis, A., Hirsch, D., Smith, N., et al. (2012) A minimum income standard for the UK. Keeping up in hard times, York: Joseph Rowntree Foundation.'

Den Hartog, A.P., Van Staveren, W.A. and Brouwer, I.D. (2006) Food habits and consumption in developing countries. Manual for field studies, Wageningen: Wageningen Academic Publishers.

Diepstraten, F. (2009) Het gezondheidsbudget, in: Storms, B. and VAn Den Bosch, K. (eds) Wat heeft een gezin minimaal nodig? Een budgetstandaard voor Vlaanderen, Leuven: Acco, 144-215.

Doyal, L. and Gough, I. (1991) A Theory of Human Need, Houndmills: Macmillan Education.

European Centre for Disease Prevention and Control (2011) Annual Epidemiological Report, Stockholm.

European Food Safety Authority (2010) 'Scientific Opinion on establishing Food-Based Dietary Guidelines. EFSA Panel on Dietetic Products, Nutrition, and Allergies (NDA)', EFSA Journal, 8(3), 1460.

Fukuyama, F. (1995) Trust: The social virtues and the creation of prosperity, New York, NY: Free Press.

GaÁl, P., Szigeti, S., PAnteli, D., et al. (2011) 'Major challenges ahead for Hungarian healthcare', $B M J, 343,1-8$.

Gibson, H. and Yiannakis, A. (2002) 'Tourist roles - Needs and the lifecourse', Annals of Tourism Research, 29(2), 358-383.

Giordano, G.N. and Lindstrom, M. (2010) 'The impact of changes in different aspects of social capital and material conditions on self-rated health over time: a longitudinal cohort study', Social Science and Medicine, 70(5), 700-710.

Goedemé, T., Storms, B. and VAn den Bosch, K. (forthcoming) 'Pilot project for the development of a common methodology on reference budgets in Europe: Proposal for a method for comparable reference budgets in Europe', Brussels: European Commission. 
Hancock, C. (2012) 'The Benefits of Physical Activity for Health and Well-being. Review', London: C3 Collaborating for Health.

Hoff, S., Van GaAlen, C., Soede, A., et al. (2010) The Minimum agreed upon. Consensual budget standards for the Netherlands, Den Hague: The Netherlands Institute for Social Research.

Holick, M.F. (2006) 'High prevalence of vitamin D inadequacy and implications for health', Mayo Clinic Proceedings, 81(3), 353-373.

Hyyppa, M.T., Maki, J., ImpivaAra, O., et al. (2006) 'Leisure participation predicts survival: a population-based study in Finland', Health Promotion International, 21(1), 5-12.

Joint WhO-FAO Expert Consultation on Diet and the Prevention of Chronic Diseases (2003) 'Diet, Nutrition, and the Prevention of Chronic Diseases: Report of a WHO-FAO Expert Consultation', Geneva: World Health Organisation.

KAWACHI, I., KenNedy, B.P. and Glass, R. (1999) 'Social Capital and Self-rated Health: a contextual analysis', American journal of Public Health, 89(8), 1187-1193.

Kemmetmüller, M. and Leitner, K. (2009) 'The Development of Reference Budgets in Austria', $3^{\text {rd }}$ edn General Assembly and Conference Reference Budgets for Social Inclusion, Vienna.

Konlaan, B.B., Theobald, H. and Bygren, L.O. (2002) 'Leisure time activity as a determinant of survival: a 26-year follow-up of a Swedish cohort', Public Health 116(4), 227-230.

Konsument Verket (2009) Estimated costs of living. The basis of decision making for reference budgets and budget advising in Sweden, Karlstad: The Swedish Consumer Agency.

LAaksonen, A. (2010) Making culture accessible. Access, participation and cultural provision in the context of cultural rights in Europe, Strasbourg: Council of Europe.

Lehtinen, A.-R., Varjonen, J., Raijas, A., et al. (2011) What Is the Cost of Living? Reference Budgets for a Decent Minimum Standard of Living in Finland, Working Paper 132, Helsinki: National Consumer Research Centre.

Lloyd-Jones, D.M., Hong, Y., Labarthe, D., et al. (2010), Defining and Setting National Goals for Cardiovascular Health Promotion and Disease Reduction The American Heart Association's Strategic Impact Goal Through 2020 and Beyond', Circulation 121(4), 586-613.

Mackenbach, J. (2006) Health Inequalities: Europe in profile, Rotterdam: University Medical Center.

Mackenbach, J., Martikainen, P., Looman, C., et al. (2005) 'The shape of the relationship between income and self-assessed health: an international study', International Journal of Epidemiology, 34, 286-293.

Mau, S. and Verwiebe, R. (2010) European Societies. Mapping structure and change, Bristol: The Policy Press. 
McKay, L., Sammut, J., Farrugia, K., et al. (2012) A Minimum Budget for a Decent Living. A research study by Caritas Malta focusing on three low-income household categories, Floriana, Malta: Caritas Malta.

Mennel, S., Murcott, A. and Van Otterloo, A.H. (1992) The Sociology of Food, Eating, Diet and Culture., London: Sage.

Murie, A. (1983) Housing Inequality and Deprivation, London: Heineman.

Orchard, T.S., PAn, X., Cheek, F., et al. (2012) 'A systematic review of omega-3 fatty acids and osteoporosis', British Journal of Nutrition, 107, S253-S260.

Petersen, P.E. (2003) The World Oral Health Report 2003: Continous improvement of oral health in the $21^{\text {st }}$ century. The approach of the WHO Global Oral Health Program, Geneva; World Health Organisation.

Portes, A. (1998) 'Social Capital. Its origins and applications in modern sociology', Annual Sociology, 24, 1-24.

Preusse, H. (2012) 'Reference budgets for counselling on how to manage private household finance - requirements and patterns based on international experience', International Journal of Consumer Studies, 36(5), 602-610.

Putnam, R. (1993) Making Democracy Work. Civic traditions in modern Italy, Princeton, NJ: Princeton University Press.

Rowntree, B.S. (2000 [1901]) Poverty: A study of town life, Bristol, The Policy Press.

Statens Institutt For FORbruksforsking (2011) Standard Budget for Consumer Expenditures, Oslo: Statens Institutt for forbruksforsking.

Stolle, D. and Hooghe, M. (2005) 'Conflicting Approaches to the Study of Social Capital', Ethical Perspectives, 10(1), 22-45.

STORMS, B. (2012) Referentiebudgetten voor maatschappelijke participatie [Reference budgets for social participation], PhD thesis, Antwerp, University of Antwerp.

Storms, B., Goedemé, T., Van den Bosch, K., et al. (2013) Towards a common framework for developing cross-nationally comparable reference budgets in Europe, ImPRovE Working Papers, Antwerp: Herman Deleeck Centre for Social Policy, University of Antwerp.

Storms, B., Goedemé, T., VAn den Bosch, K. et al. (2014) Review of current state of play on reference budget practices at national, regional, and local level, Brussels: European Commission.

Storms, B., Penne, T. and Van Thielen, L. (forthcoming) De doeltreffendheid van minimum inkomensbescherming anno 2013. Wat leren referentiebudgetten? Antwerp: University of Antwerp.

Storms, B. and VAN DEN Bosch, K. (2009a) Wat heeft een gezin minimaal nodig? Een budgetstandaard voor Vlaanderen, Leuven / Den Haag: Acco.

STORMS, B. and VAN DEN BosCH, K. (2009b) What income do families need for social participation at the minimum? A budget standard for Flanders, Antwerp: Herman Deleeck Centre for Social Policy, University of Antwerp. 
Thoits, P.A. (1983) 'Multiple identities and psychological well-being: A reformulation and test of the social isolation hypothesis', American Sociological Review, 174187.

Toerisme Vlaanderen (2007) Profielwijzer voor de toerist. Basismotivaties van de vakantiegangers uit de buurlanden.

UN General Assembly (1989) Convention on the Rights of the Child, New York, NY.

Van den Bosch, K., Schuerman, N., Marchal, S., et al. (forthcoming) Estimating the housing cost for a modest but adequate dwelling in EU cities: first results from EU-SILC, Antwerp: Herman Deleeck Centre for Social Policy, University of Antwerp.

Van Thielen, L., Deflandre, D., Baldewijns, K., et al. (2010) 'Minibudget. Wat hebben gezinnen nodig om menswaardig te leven in België?', Onderzoek gefinancierd door Federaal Wetenschapsbeleid in opdracht van de POD MI, Geel: Katholieke Hogeschool Kempen.

Vartanian, L.R., Schwartz, M.B. and Brownell, K.D. (2007) 'Effects of soft drink consumption on nutrition and health: A systematic review and meta-analysis', American Journal of Public Health, 97(4), 667-675.

Vassileva, B. (2009) 'Bulgaria. Case Study', in WarnaAr, M. and Luten, A. (eds) Handbook of reference budgets. On the design and application of reference budgets, Utrecht: Nibud, 69-81.

World Health Organisation (1982) Manuals on Child Mental Health and Psychosocial Development, Geneva, WHO.

Willems, S. (2005) The socio-economic gradient in health: a never ending story? A descriptive and explorative study in Belgium, Gent: UGent.

Williams, P.G. (2012) 'Evaluation of the evidence between consumption of refined grains and health outcomes', Nutrition Reviews, 70(2), 80-99. 